\title{
Can We Predict De Novo Urge Incontinence by Perineal Ultrasound?
}

\author{
Judith Lleberia*, Josep Pubill, Montserrat Mestre, Emma Garcia, Jose M. Gris, Eduardo Bataller \\ Hospital Parc Taulí, Sabadell, Spain \\ Email: *lleberia@hotmail.com
}

How to cite this paper: Lleberia, J., Pubill, J., Mestre, M., Garcia, E., Gris, J.M. and Bataller, E. (2018) Can We Predict De Novo Urge Incontinence by Perineal Ultrasound? Open Journal of Obstetrics and Gynecology, 8, 185-197.

https://doi.org/10.4236/ojog.2018.83022

Received: January 20, 2018

Accepted: March 12, 2018

Published: March 15, 2018

Copyright $\odot 2018$ by authors and Scientific Research Publishing Inc. This work is licensed under the Creative Commons Attribution International License (CC BY 4.0).

http://creativecommons.org/licenses/by/4.0/

\begin{abstract}
Introduction: Urinary incontinence affects over 200 million people worldwide [1]. Tension free vaginal tape is the standard surgical treatment for stress urinary incontinence. De novo urge urinary incontinence is a long-term complication of this treatment with a significant impact in the quality of life of these patients. Objective: The major aim of this study is to assess the correlation between perineal ultrasonography findings and the incidence of de novo urge urinary incontinence. Material and Methods: A prospective observational study was designed. Patients with stress urinary incontinence diagnosed by clinical and urodynamic findings submitted to a tension-free vaginal tape surgery were included. International Consultation on Incontinence Questionnaire-Short Form (ICIQ-SF) and introital perineal ultrasound were performed before surgical intervention (I-STOP $\odot$ ). Clinical and ultrasound re-evaluation were executed six months after surgery. Stress urinary incontinence was defined according to the ICS-IUGA. Data were recorded using a Microsoft Access database and statistical analysis using SAS๑. Results: Bladder thickness equal to or below $6 \mathrm{~mm}$ has a low positive predictive value (PPV, 0.55), but a negative predictive power (NPP) of 0.72. Following surgery, a slight increase in postvoid residue is observed. Considering demographic data, an increase of 5 points in body mass index (BMI) resulted in an odds ratio (OR) of 1.74 of presenting de novo urge urinary in continence. Conclusions: In patients submitted to a tension-free vaginal tape surgery, high BMI seems to be associated with a higher rate of de novo urge urinary incontinence. Preoperative bladder wall thickness below $6 \mathrm{~mm}$ seems predict absence of this complication.
\end{abstract}

\section{Keywords}

Stress Urinary Incontinence, De Novo Urge, Tension Free Sling, Perineal Ultrasound, Bladder Thickness, Residual Postvoid, BMI 


\section{Introduction}

Stress urinary incontinence is the most frequent type of urinary incontinence in developed countries [1] [2]. When conservative approach with pelvic floor rehabilitation fails, surgery with tension-free vaginal tape is the gold standard treatment [3] [4]. One of its more frequent long-term complications is the debut of de novo urge incontinence, defined as a strong desire to urinate that cannot be postponed and that appears after the anti-incontinence surgery performed for stress urinary incontinence, and persists for more than 6 months [5]. It may or not be associated with incontinence. Its incidence is variable according to literature (3.1\% - 25.9\%) [6] [7] [8], and the underlying causes remain unclear.

On the other hand, perineal ultrasonography results from the application of the ultrasonography technique (classically gynaecological) to the visualization of structures of the lowest part of the pelvis: pubic symphysis, urethra, urinary bladder and anal canal [9]. Both transvaginal and abdominal transducers can be used, locating them at the introit level between labia minora. For this reason, it's also called introital or translabial ultrasonography [10].

The objective of this study is to assess preoperative anatomical factors that may predict the onset of de novo urgency after the anti-incontinence surgery with tension-free vaginal tape to correct the stress urinary incontinence.

\section{Patients and Methods}

An observational prospective study was performed, in which women with stress urinary in continence with indication for surgical treatment (transobturator tension-free suburethral vaginal tape technique I-STOP ${ }^{\bowtie}$ ) were included after voluntarily accepting to participate in the study.

\section{Inclusion criteria}

- Women over 18 years of age with stress urinary incontinence.

- Clinical and urodynamic diagnosis of this incontinence.

- All study participants must have the ability to decide, understand and agree to participate in the study, giving informed consent.

\section{Exclusion criteria}

- Urge or mixed urinary incontinence clinical and/or urodynamic.

- Physical findings suggestive of fixed urethra.

- Undercurrent pathology that interferes in the assessment of incontinence or in the performance of surgery.

Medical interview and physical exploration of all patients was at the Pelvic Floor Unit of the Gynaecology Service of our hospital. The International Consultation on Incontinence-Short Form (ICIQ-SF) questionnaire validated to Spanish language in 2004 by Espuña et al. [11] was filled. Later, an urodynamic study with flowmetry and cystometry was performed.

Before surgery, a perineal ultrasound was performed evaluating urethral hypermobility, bladder volume and bladder wall thickness. Hypermobility was assessed by measuring several distances (urethroptosis, urethral sliding and pu- 
bovesical distance) and angles (vesical and retro-urethral) as shown in Figure 1. Premicturition or basal bladder volume and postmicturition residue were calculated by using the formula described by Haylen, whilst bladder wall thickness was measured according to Robinson.

Surgery consisted in the placement of an inside-out transobturator suburethral tension-free vaginal tape. In our series, we implemented the I-STOP® mesh (manufactured by CL Medical and distributed by B-Braun Surgical). In patients with simultaneous prolapse, additional repair surgery was performed according to the affected compartment.

Follow up was performed in the outpatient clinic at 1, 3 and 6 months following surgery. Perineal ultrasonographic reassessment was repeated 3 months after surgery, stressing bladder volumes, and bladder wall thickness and mesh visualization. At 6-month follow up, the presence of urge symptoms and/or urinary urgency leakage was assessed, and correlated with ultrasound parameters. Moreover, the ICIQ-SF questionnaire was repeated.

Collected data was recorded in a Microsoft Access database and the statistical analysis performed in SAS (version 8.2; SAS Institute, Inc, Cary, NC). Following descriptive analysis, a comparative analysis was done between the groups previously described with chi-square test for categorical data and Student's t-test for continuous data, in a normal Gaussian distribution. When population could not be assumed to be normally distributed the Wilcox on signed-rank test was used. The sample size was determined with an estimation of 85 patients. The study was approved by the Clinical Research Ethical Committee of our hospital (CEIC 2009-588).

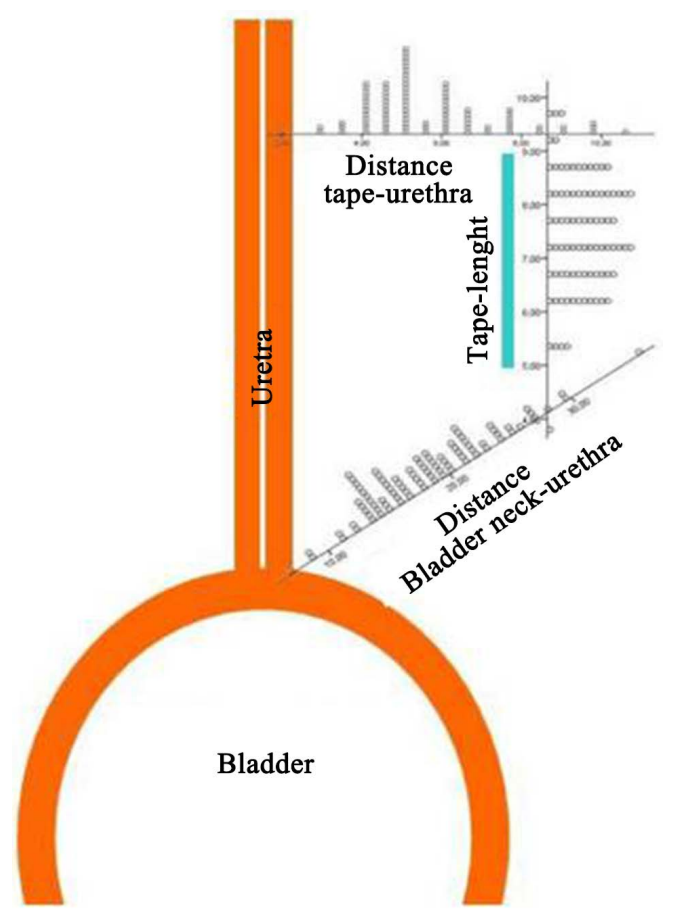

Figure 1. Tape localization. 


\section{Results}

A total of 87 patients were included in the present study. De novo urinary urgency was reported in 25 cases (28.74\%). Among these, 19 patients presented incontinence. A total of 62 patients remained asymptomatic. Among these newly diagnosed cases, 14 presented a ICIQ-SF score over 7, meaning that de novo urinary urgency had an impact in the quality of life in $16.1 \%$ of the patients.

Demographic data

Patients average age was $57.32( \pm 10.57)$, without significant differences between groups. Mean body mass index (BMI) among the studied population was 29.45 ( \pm 4.72 ), being significantly different between asymptomatic and newly diagnosed urinary urgency patients $(28.73 \pm 4.57$ and $31.22 \pm 4.71$, respectively; $p=0.025)$. The odds of developing de novo urinary urgency following surgery was 1.74 higher in patients with a 5 points increase in the BMI $\left(\mathrm{e} \times\left(5^{\star} 1.111\right)=\right.$ $1.74)$.

In the studied population, $8.04 \%$ of the patients $(n=7)$ had previous history of pelvic organ prolapse surgery. These included 4 vaginal hysterectomies (3 with simultaneous anterior colpoplasty) and 2 anterior and 1 posterior colpoplasties.

ICIQ-SF

Preoperative quality of life was assessed with the Spanish validated version of the ICIQ-SF questionnaire, with a global score of $15.20( \pm 3.36)$. The initial mean score was $15.08( \pm 1.48)$ in the asymptomatic group and $15.48( \pm 3.31)$ in the urge urinary group, being $15.17( \pm 3.79)$ in the group with urge incontinence without impact on the quality of life and $15.77( \pm 2.25)$ in the group with urinary urgence with ICIQ-SF $>7$, without significant differences between patients. Detailed data on Table 1.

Baseline urodynamic study

Previously to surgery, all patients were assessed with cystometry and flowmetry with the urodynamic diagnosis of stress urinary incontinence.

\section{Baseline ultrasound parameters}

Urethral hypermobility

Basal urethroptosis (defined as the difference between the distance from pubic symphysis to the urethra with and without Valsalva manoeuvre, previously to micturition) presented lower mean values in all cases, without significant differences between groups, while postvoid urethroptosis displayed no differences between groups neither when comparing with basal values. Basal pubovesical distance (defined as the difference between the distance from pubic symphysis to bladder neck with and without Valsalva manoeuvre, previously to micturition) presented variability without correlation with outcome. Similar results were observed in postmicturition pubovesical distance. Mean baseline and postmicturition global sliding (difference between the distance from bladder neck and urethra with and without Valsalva man oeuvre, assessed previously and postmicturition, respectively) was $7.23 \mathrm{~mm}( \pm 6.02)$ and $5.70 \mathrm{~mm}( \pm 4.95)$. All groups displayed differences in baseline and postmicturition sliding (Table 2). 
Table 1. Demographic results.

\begin{tabular}{|c|c|c|c|c|}
\hline & $\begin{array}{l}\text { Total } \\
\mathrm{N}=87\end{array}$ & $\begin{array}{l}\text { Healing group } \\
\qquad N=62\end{array}$ & $\begin{array}{c}\text { De novo urge } \\
\quad \mathrm{N}=25\end{array}$ & $\begin{array}{l}\text { Probability } \\
\text { (p) }\end{array}$ \\
\hline $\begin{array}{c}\text { Age at years } \\
\text { (average }( \pm S D) \text { ) }\end{array}$ & $57.32( \pm 10.57)$ & $57.05( \pm 10.49)$ & $58.00( \pm 10.96)$ & 0.210 \\
\hline $\begin{array}{c}\text { Children } \\
\text { (median (range)) }\end{array}$ & $2(0-9)$ & $2(0-9)$ & $2(1-5)$ & 0.710 \\
\hline $\begin{array}{c}\text { BMI } \\
\left(\text { weight } / \text { height }^{2}\right) \\
(\text { average }( \pm S D))\end{array}$ & $29.45( \pm 4.72)$ & $28.73( \pm 4.57)^{\star}$ & $31.22( \pm 4.71)^{\star}$ & 0.008 \\
\hline $\begin{array}{c}\text { Testing Oxford } \\
\text { (average }( \pm S D))\end{array}$ & $2.24( \pm 1.74)$ & $2.18( \pm 1.48)$ & $2.40( \pm 2.29)$ & 0.152 \\
\hline $\begin{array}{c}\text { ICIQ-SF } \\
\text { preoperative } \\
\text { (average }( \pm S D) \text { ) }\end{array}$ & $15.20( \pm 3.36)$ & $15.08( \pm 1.48)$ & $15.48( \pm 3.31)$ & 0.893 \\
\hline
\end{tabular}

Table 2. Perineal ultrasound measurements preoperative (Average $( \pm \mathrm{SD})$ ).

\begin{tabular}{|c|c|c|c|}
\hline & $\begin{array}{l}\text { Total } \\
\mathrm{N}=87\end{array}$ & $\begin{array}{l}\text { Healing group } \\
\qquad \mathrm{N}=62\end{array}$ & $\begin{array}{l}\text { De novo urge group } \\
\qquad \mathrm{N}=25\end{array}$ \\
\hline $\begin{array}{c}\text { Uretroptosis } \\
\text { prevoiding }(\mathrm{mm})\end{array}$ & $-2.67( \pm 3.93)$ & $-2.74( \pm 3.99)$ & $-3.50( \pm 3.72)$ \\
\hline $\begin{array}{c}\text { Uretroptosis } \\
\text { postvoiding }(\mathrm{mm})\end{array}$ & $-2.91( \pm 4.19)$ & $-2.90( \pm 3.64)$ & $-2.91( \pm 5.40)$ \\
\hline $\begin{array}{c}\text { Pubovesical } \\
\text { distance } \\
\text { prevoiding }(\mathrm{mm})\end{array}$ & $-0.25( \pm 5.95)$ & $-0.68( \pm 5.80)$ & $0.83( \pm 6.28)$ \\
\hline $\begin{array}{c}\text { Pubovesical } \\
\text { distance } \\
\text { postvoiding }(\mathrm{mm})\end{array}$ & $-0.40( \pm 5.88)$ & $-0.34( \pm 6.05)$ & $-0.56( \pm 5.58)$ \\
\hline $\begin{array}{c}\text { Sliding } \\
\text { prevoiding }(\mathrm{mm})\end{array}$ & $7.23( \pm 6.02)$ & $7.16( \pm 4.32)$ & $7.40( \pm 9.07)$ \\
\hline $\begin{array}{c}\text { Sliding } \\
\text { postvoiding }(\mathrm{mm})\end{array}$ & $5.70( \pm 4.95)$ & $5.88( \pm 5.05)$ & $5.24( \pm 4.77)$ \\
\hline $\begin{array}{l}\text { Alfa angle } \\
\text { (grade) }\end{array}$ & $122.20( \pm 20.47)$ & $123.42( \pm 19.65)$ & $119.16( \pm 22.50)$ \\
\hline $\begin{array}{l}\text { Beta angle } \\
\text { (grade) }\end{array}$ & $25.54( \pm 16.12)$ & $25.69( \pm 16.35)$ & $25.16( \pm 15.83)$ \\
\hline
\end{tabular}

All calculated angles, including bladder angle $(\alpha)$ and retro-urethral $(\beta)$, both baseline and with Valsalva manoeuvre are presented in Table 2, without differences between groups.

\section{Bladder volume}

Global average baseline (premicturition) bladder volume was $97.14 \mathrm{ml}$ $( \pm 105.15), 99.92 \mathrm{ml}( \pm 106.11)$ in the group without urge, $90.24 \mathrm{ml}( \pm 104.57)$ in the urinary urge, $85.83 \mathrm{ml}( \pm 130.38)$ in the patients with urge and low ICIQ-SF and $94.31 \mathrm{ml}( \pm 79.05)$ in patients with urge and ICIQ-SF $>7$.

Average postmicturition bladder volume (postvoid residue) before surgery was $14.75 \mathrm{ml}( \pm 38.66)$, being $16.05 \mathrm{ml}( \pm 41.02)$ in the cured patients, $11.52 \mathrm{ml}$ 
$( \pm 32.62)$ in the patients with urge, $15.25 \mathrm{ml}( \pm 44.28)$ in the el group with urge without impact on the quality of life and $8.08 \mathrm{ml}( \pm 2.42)$ in the group with urge and significant impact in quality of life (Table 3 ).

Bladder wall thickness

Global average premicturition bladder wall thickness was $4.80 \mathrm{~mm}( \pm 0.99)$. In the women considered cured it was $4.76 \mathrm{~mm}( \pm 0.94)$ and in those with urinary urge $4.90 \mathrm{~mm}( \pm 1.10)$. Among these, it was $4.97 \mathrm{~mm}( \pm 1.14)$ in those with low impact on the ICIQ-SF and $4.84 \mathrm{~mm}( \pm 1.11)$ in the cases with significant impact on quality of life.

Postvoid assessment of bladder wall thickness showed a global thickness of $5.88 \mathrm{~mm}( \pm 1.43)$, being $5.78 \mathrm{~mm}( \pm 1.39)$ in the cured patients and $6.14 \mathrm{~mm}$ $( \pm 1.53)$ in those with urinary urge. In the cases with low and significant impact in the ICIQ-SF it was $5.76 \mathrm{~mm}( \pm 1.67)$ and $6.50 \mathrm{~mm}( \pm 1.34)$, respectively (Table 4).

\section{Surgical procedure}

All patients were submitted to inside-out transobturator suburethral tension-free vaginal tape technique (produced by CL Medical, distributed by I-STOP@, B-Braun, Aesculap AG, Tuttlingen, Germany).

\section{Simultaneous procedures}

Simultaneously to the incontinence surgery, 31 patients were additionally submitted to: 15 vaginal hysterectomies (17.24\%), 19 simple anterior colpoplasties $(21.83 \%), 5$ anterior colpoplasties with mesh and anchoring (5.75\%) and 3 posterior colpoplasties with mesh and anchoring (3.45\%). No statistical correlation was found between prolapse surgery and de novourinary urge.

Postoperative ultrasound parameters

Hypermobility

Table 3. Bladder volume preoperative.

\begin{tabular}{cccccc}
\hline & $\begin{array}{c}\text { Total } \\
\mathrm{N}=87\end{array}$ & $\begin{array}{c}\text { Healing group } \\
\mathrm{N}=62\end{array}$ & $\begin{array}{c}\text { De novo URGE De novo URGE De novo URGE } \\
\text { group } \mathrm{N}=25\end{array}$ & ICIQ $\leq 7 \mathrm{~N}=11$ ICIQ $>7 \mathrm{~N}=14$ \\
\hline $\begin{array}{c}\text { Basal } \\
\text { volume (ml) }\end{array}$ & $97.14( \pm 105.15)$ & $99.92( \pm 106.11)$ & $90.24( \pm 104.57)$ & $85.83( \pm 130.38)$ & $94.31( \pm 79.05)$ \\
$\begin{array}{c}\text { Residual } \\
\text { volume }(\mathrm{ml})\end{array}$ & $14.75( \pm 38.66)$ & $16.05( \pm 41.02)$ & $11.52( \pm 32.62)$ & $15.25( \pm 44.28)$ & $8.08( \pm 17.46)$ \\
\hline
\end{tabular}

Table 4. Bladder wall thickness preoperative.

\begin{tabular}{cccccc}
\hline & $\begin{array}{c}\text { Total } \\
\mathbf{N}=\mathbf{8 7}\end{array}$ & $\begin{array}{c}\text { Healing } \\
\text { group } \\
\mathbf{N}=\mathbf{6 2}\end{array}$ & $\begin{array}{c}\text { De novo URGE } \\
\text { group N }=25\end{array}$ & $\begin{array}{c}\text { De novo URGE } \\
\text { ICIQ } \leq 7 \mathrm{~N}=11\end{array}$ & $\begin{array}{c}\text { De novo URGE } \\
\text { ICIQ }>7 \text { N }=14\end{array}$ \\
$\begin{array}{c}\text { BWT } \\
\text { basal }(\mathrm{mm})\end{array}$ & $4.80( \pm 0.99)$ & $4.76( \pm 0.94)$ & $4.90( \pm 1.10)$ & $4.97( \pm 1.14)$ & $4.84( \pm 1.11)$ \\
$\begin{array}{c}\text { BWT } \\
\text { postvoid }(\mathrm{mm})\end{array}$ & $5.88( \pm 1.43)$ & $5.78( \pm 1.39)$ & $6.14( \pm 1.53)$ & $5.76( \pm 1.67)$ & $6.50( \pm 1.34)$ \\
\hline
\end{tabular}


All average sliding distances decreased following surgery, both before and after voiding, mainly in the group that did not develop urinary urge following surgery. In the comparative study of the distance from pubic symphysis to the urethra and urethroptosis, no differences were found between the variables, pre o post-micturition and pre and post-surgery, neither between the different groups of patients. Baseline and Valsalva measurements of distances and angles are shown in Table 5.

\section{Bladder volume}

Average premicturition bladder volume following surgery was $95.41 \mathrm{ml}$, without differences between healed and new onset urinary urge groups $(p=0.830)$. Nonetheless these were different when considering urinary urge subgroups with ICIQ-SF $<7$ or $\geq 7$. The group with a significant impact in the quality of life presented increased bladder volumes when compared with other groups (healed and urinary urge with ICIQ-SF $<7), 134.23 \mathrm{ml}$ vs. $95.05 \mathrm{ml} / 55.25 \mathrm{ml}(p=0.019)$.

The difference between the average premicturition bladder volume before and after surgery was not statistically significant: $97.14 \mathrm{ml}$ vs. $95.41 \mathrm{ml}, p=0.721$. Also, the different sub groups (healing, urinary urgence with ICIQ-SF $<7$ and $\geq 7$ failed to reveal differences $(p=0.833, p=0.752, p=0.292$ and $p=0.333$, respectively).

Average postoperative postmicturition bladder volume (postvoid residue) was not different between healed and urinary urge groups: $27.43 \mathrm{ml}$ vs. $25.75 \mathrm{ml}, p=$ 0.316 . Additionally, no differences were found between subgroups of urinary urge when considering the ICIQ-SF score.

Postmicturition bladder volume (postvoid residue) before and following anti-incontinence surgery revealed statistically significant differences both globally $(p=0.005)$ and in the group of patients with urinary urge $(p=0.031)$.

Table 5. Perineal ultrasound measurements postoperative (Average $( \pm \mathrm{SD})$ ).

\begin{tabular}{|c|c|c|c|}
\hline & $\begin{array}{c}\text { Total } \\
\mathrm{N}=87\end{array}$ & $\begin{array}{l}\text { Healing group } \\
\qquad N=62\end{array}$ & $\begin{array}{l}\text { De novo urge group } \\
\qquad \mathrm{N}=25\end{array}$ \\
\hline $\begin{array}{c}\text { Uretroptosis } \\
\text { prevoiding }(\mathrm{mm})\end{array}$ & $-1.57( \pm 3.31)$ & $-1.91( \pm 3.31)$ & $-0.75( \pm 3.22)$ \\
\hline $\begin{array}{c}\text { Uretroptosis } \\
\text { postvoiding }(\mathrm{mm})\end{array}$ & $-0.31( \pm 3.28)$ & $-0.33( \pm 3.46)$ & $-0.29( \pm 2.84)$ \\
\hline $\begin{array}{l}\text { Pubovesical distance } \\
\text { prevoiding }(\mathrm{mm})\end{array}$ & $-0.44( \pm 4.32)$ & $-0.27( \pm 4.49)$ & $-0.87( \pm 3.91)$ \\
\hline $\begin{array}{l}\text { Pubovesical distance } \\
\text { postvoiding }(\mathrm{mm})\end{array}$ & $0.34( \pm 4.27)$ & $0.73( \pm 4.07)$ & $-0.62( \pm 4.66)$ \\
\hline $\begin{array}{c}\text { Sliding } \\
\text { prevoiding }(\mathrm{mm})\end{array}$ & $5.13( \pm 3.63)$ & $5.48( \pm 3.30)$ & $4.27( \pm 4.28)$ \\
\hline $\begin{array}{c}\text { Sliding } \\
\text { postvoiding }(\mathrm{mm})\end{array}$ & $4.36( \pm 3.89)$ & $4.61( \pm 3.82)$ & $3.72( \pm 4.07)$ \\
\hline $\begin{array}{l}\text { Alfa angle } \\
\text { (grades) }\end{array}$ & $114.80( \pm 15.98)$ & $114.24( \pm 15.55)$ & $116.20( \pm 17.25)$ \\
\hline $\begin{array}{l}\text { Beta angle } \\
\text { (grades) }\end{array}$ & $25.54( \pm 16.12)$ & $25.69( \pm 16.35)$ & $25.16( \pm 15.83)$ \\
\hline
\end{tabular}


Non-parametric Wilcoxon test revealed significant differences regarding the increase in postvoid residue following surgery (difference between preoperative postvoid residue and postoperative postvoid residue) $(p=0.002)$. Following placement of suburehthral sling a mild increase in postvoid residue was observed, probably due to a more prominent increase in the urinary urge group ( $p$ $=0.031)$, as no significant differences were found in the healed group $(p=0.06)$.

\section{Bladder wall thickness}

Postoperative pre and postmicturition bladder wall thickness failed to reveal differences between groups (healed, urinary urge, urinary urge ICIQ-SF $<7$ and urinary urge ICIQ-SF $\geq 7, p>0.05$ ).

Premicturition bladder wall thickness before and following surgery were significantly different only in a global analysis $(p=0.023)$, without significant differences between groups. Pre and postoperative postmicturition bladder wall thickness failed to reveal differences.

A bladder wall thickness equal or above $6 \mathrm{~mm}$ was observed in $21.84 \%$ of the patients, and in $47.37 \%$ of cases of new onset urinary urge $(p=0.0423)$. Bladder wall thickness equal or above6 $\mathrm{mm}$ presented a sensitivity and specificity for detecting urinary urge of $36 \%$ and $83.87 \%$, respectively, proximate to the accuracy of the preoperative exploration (positive predictive value $=0.36$, negative predictive value $=0.84$ ).

No differences were found on bladder wall thickness when considering body mass index categories of normal weight, overweight and obesity $(p=0.403)$. When considering body weight categories, bladder wall thickness $\geq 6 \mathrm{~mm}$ failed to accurately predict the development of de novo urinary urge. Sensitivity and specificity according to BMI were similar to those among global cases.

Postoperatively, $12.64 \%$ of the patients in our study presented a premicturition bladder wall thickness $\geq 6 \mathrm{~mm}$ and, among these, 54.55\% developed urinary urge $(p=0.043)$. Despite the sensitivity of this measure (bladder wall thickness $\geq 6 \mathrm{~mm}$ ) was low $(24.0 \%)$, it presented a very high specificity $(91.94 \%$; PPV $=$ $0.55, \mathrm{NPV}=0.92)$. In other words, a preoperative premicturition bladder wall thickness below $6 \mathrm{~mm}$ carried out a low probability of developing de novo urinary urge incontinence.

As it was a predictive factor, we considered important to measure the bladder wall thickness in relation with the BMI. The objective was to determinate if the premictional bladder wall thickness was an independent factor from the BMI.

The comparison between women with normal weight, overweight and obesity showed that there were no statistically significant differences on the bladder wall thickness $p=0.403$. BMI did not affect the ability of bladder wall thickness above $6 \mathrm{~mm}$ in predicting the development of urinary urge. Global values of sensitivity and specificity were similar, regardless of weight group.

Location of the mesh

The length of the mesh, the distance from the mesh to the urethra and the distance from the mesh to the bladder neck before and after micturition were similar between groups. 


\section{Discussion}

Surgical correction of stress urinary incontinence consists of a standardized technique with a long term high healing rate around $90 \%$ at 17 years of follow up, as reported by Nilsson [12] in 2013. Randomized studies and meta-analysis from 2014 comparing techniques [13] and approaches [14] failed to reveal differences between outcomes and complications between the types of meshes.

When considering incidence and impact in the quality of life of our patients, the main long term complication is de novo urge urinary incontinence. With an estimated incidence between $3.1 \%$ and $25.9 \%$ following surgery, its frequency increases with age, parity and history of c-section according to Holmgren [15].

Also, BMI resulted determinant in the surgical results. Literature previously highlighted obesity as one of the more influent factors in the appearance of urinary incontinence [16].

Analyzing the impact of higher body weight on the different type of urinary incontinence, in a population study with 2001 women, Vaunhan [17] reported a relative risk between obesity and stress urinary incontinence of 1.9 (IC $1.2-3.0$ ), and with urge urinary incontinence of 3.0 (IC $1.2-7.4$ ). In the same direction, Subak [18] reported in 2009 the effect of losing weight and practicing exercise in a population with BMI between 25 and 40. Later, the same research group reviewed published data, concluding that a 5 -unit gain in the BMI was associated with an increase of $20 \%-70 \%$ in the incidence of urinary incontinence [19]. This relation was present for all types of urinary incontinence, being particularly significant in cases of urge and severe urinary incontinence. Our data further supports these findings, as in our series a 5 points increase in the BMI was associated with an odds ratio of 1.74 of developing UI.

Focusing on ultrasonographic parameters, the preoperative residual volume was easy to assess using standard ultrasound measures [20] [21]. In a review about ultrasonographic measurement of residual volume, Haylen considers it as a good tool for assessing bladder-emptying function [22].

In our study, no preoperative differences were found between groups concerning pre or postmicturition or bladder volumes.

In 1996, Vikram Khullar reported the association between a bladder wall thickness over $5 \mathrm{~mm}$ and the urodynamic diagnosis of detrusor hyperactivity [23], in accordance with our data. In 2002, Robinson published the triple measure standardization [24] with similar results. Leks kulchai and Dietz [25] also reported a relation between bladder wall thickness and overactive bladder. More recently, high bladder wall thickness measured with 3D ultrasound by Khullar and colleagues was also associated with this pathology [26]. Adjusting the results by BMI supported it as an independent predictive factor. Regarding surgical outcomes, we report $66.67 \%$ of continent women. In terms of quality of life $67.8 \%$ presented a 0 score in the ICIQ-SF, and $80.5 \%$ had a score equal or less than 7 . Overall, $91.95 \%$ of the patients of this study were satisfied with the procedure and would do it again, in accordance with previous published data [12]. 
We found a very high rate of urinary urgency in our study (28.7\%), although the rate reduced to $16.1 \%$ if only ICIQ-SF scores $\geq 7$ were considered. In literature, the incidence of de novo urgency urinary incontinence ranges from 5.2\% and $23.2 \%$ [6] [7] [27].

Postoperative ultrasound presented as an anatomical description of the bladder (bladder wall thickness and postvoid residue) and urethral mobility after surgery. Mean pre and postmicturition measures of urethral sliding were lower postoperatively, particularly in the group that did not develop urinary urgency.

Following the surgery, post void residue increased in all groups, particularly in the group developing urgency, in a statistically significant way. Population studies in women between 55 and 75 years reported an association between post void residues over 100 and $200 \mathrm{ml}$, and voiding frequency and urge urinary incontinence, respectively [28]. In our series, the mean difference in volume is less than $100 \mathrm{ml}$.

Bladder wall thickness was interesting for its negative predictive value. In 2002, Robinson reported a relation between a transvaginal measure of the bladder wall thickness over $5 \mathrm{~mm}$ and overactive bladder [24]. Latthe reviewed the usefulness of a total bladder wall thickness over $5 \mathrm{~mm}$ in predicting overactive bladder, estimating sensitivity between $40 \%-84 \%$ and specificity between $78 \%$ - 89\%. In our study, despite a lower sensibility, we report a higher specificity.

The visualization of the mesh by ultrasound turns simple with some training, being reproducible with good intra and interobserver correlation [29]. In our series, the changes in the position of the mesh did not correlate with the appearance of de novo urgency, alike to what DeTayrac reported [30]. Other authors correlate the obstruction by the mesh with de novo urgency [28].

In our opinion, one of the major strengths of our study is the use of perineal (or translabial) ultrasound, a safe technique, radiation free, simple, cheap, easily accessible and with motion tracking. The use of a vaginal probe 7.5 MHZ and a 2 $\mathrm{D}$ study turned the exploration reproducible and accessible to the standard gynecological consulting room. A six months training period before the study, avoided the interference of the learning curve in the results, and made the technique easily applicable in the daily clinical practice. Another strength of the study was its prospective nature, allowing a rigorous follow up according to the study design. The high number of variables, mostly quantitative, permitted a specific statistical analysis.

As a weakness of the study, we have to consider that despite including patients with stress urinary incontinence, 31 women were submitted to additional concomitant surgery, a common scenario in daily practice. On the other hand, the postoperative urodynamic study was not performed in all patients, and thus, the assessment of urgency was based on clinical presentation not urodynamic evaluation. Global incidence of urgency resulted to be high (28.74\%), probably because anamnesis of urge was strict. In fact, the repercussion in the quality of life of the patients was $16.09 \%$, similar to what is reported in the literature. Follow 
up time was 6 months, which is considered adequate to the development of micturition urge symptoms, although it would be interesting to know longer-term results. On the other hand, and despite the modality of ultrasound and the measurements used in this study were selected after reviewing the literature, the great variety of measures, approaches and measuring zones forced to apply some arbitrary criteria to constrict the measures to what seemed to be more feasible, helpful, reproducible and applicable to the daily clinical practice. For example, the choice for a $2 \mathrm{D}$ technique was due to a matter of the availability in the basic gynecologic consulting room.

Finally, our results support that preoperative anthropometric (BMI) and ultrasonographic parameters (premicturition bladder wall thickness) seem to determine the postoperative risk of developing de novo urge incontinence.

\section{References}

[1] Norton, P. and Brubaker, L. (2006) Urinary Incontinence in Women. The Lancet, 367, 57-67. https://doi.org/10.1016/S0140-6736(06)67925-7

[2] Hunskaar, S., Lose, G., Sykes, D. and Voss, S. (2004) The Prevalence of Urinary Incontinence in Women in Four European Countries. BJU International, 93, 324-330. https://doi.org/10.1111/j.1464-410X.2003.04609.x

[3] Ulmsten, U., Henriksson, L., Johnson, P. and Varhos, G. (1996) An Ambulatory Surgical Treatment of Female Urinary Incontinence. International Urogynecology Journal, 7, 81-86. https://doi.org/10.1007/BF01902378

[4] Delorme, E. (2001) Transobturator Urethral Suspension: Mini-Invasive Procedure in the Treatment of Stress Urinary Incontinence in Women. Progres En Urologie, 11, 1306-1313.

[5] Haylen, B.T., de Ridder, D., Freeman, R.M., Swift, S.E., Berghmans, B., Lee, J., et al. (2010) An International Urogynecological Association (IUGA)/International Continence Society (ICS) Joint Report on the Terminology for Female Pelvic Floor Dysfunction. International Urogynecology Journal, 21, 5-26.

https://doi.org/10.1007/s00192-009-0976-9

[6] Celebi, I., Güngördük, K. and Ark, C. (2009) Results of the Tension-Free Vaginal Tape Procedure for Treatment of Female Stress Urinary Incontinence: a 5-Year Follow-Up Study. Archives of Gynecology and Obstetrics, 279, 463-467. https://doi.org/10.1007/s00404-008-0805-2

[7] Lee, K.S., Choo, M.S., Doo, C.Y., Han, D.H., Lee, Y.S., Kim, J.Y., et al. (2008) The Long Term (5-years) Objective TVT Success Rate Does Not Depend on Predictive Factors at Multivariate Analysis a Multicentre Retrospective Study. European Urology, 53, 176-183. https://doi.org/10.1016/j.eururo.2007.08.033

[8] Giberti, C., Gallo, F., Cortese, P. and Schenone, M. (2007) Transobturator Tape for Treatment of Female Stress Urinary Incontinence: Objective and Subjective Results after a Mean Follow-Up of Two Years. Urology, 69, 703-707. https://doi.org/10.1016/j.urology.2007.01.013

[9] Shek, K.L. and Dietz, H.P. (2013) Pelvic Floor Ultrasonography: An Update. Minerva Ginecologica, 65, 1-20.

[10] Dietz, H.P. (2004) Ultrasound Imaging of the Pelvic Floor. Part I: Two-Dimensional Aspects. Ultrasound in Obstetrics and Gynecology, 23, 80-92. https://doi.org/10.1002/uog.939 
[11] Espuña Pons, M., Rebollo Álvarez, P. and Puig Clota, M. (2004) Validación de la versión española del International Consultation on Incontinence Questionnaire-Short Form. Un cuestionario para evaluar la incontinencia urinaria. Medicina Clinica, 122, 288-292. https://doi.org/10.1016/S0025-7753(04)74212-8

[12] Nilsson, C.G., Palva, K., Aarnio, R., Morcos, E. and Falconer, C. (2013) Seventeen Years' Follow-Up of the Tension-Free Vaginal Tape Procedure for Female Stress Urinary Incontinence. International Urogynecology Journal, 24, 1265-1269.

https://doi.org/10.1007/s00192-013-2090-2

[13] Schimpf, M.O., Rahn, D.D., Wheeler, T.L., Patel, M., White, A.B., Orejuela, F.J., et al. (2014) Sling Surgery for Stress Urinary Incontinence in Women: A Systematic Review and Meta-Analysis. American Journal of Obstetrics \& Gynecology, 211, 71.e1-71.e27. https://doi.org/10.1016/j.ajog.2014.01.030

[14] Madhuvrata, P., Riad, M., Ammembal, M.K., Agur, W. and Abdel-Fattah, M. (2012) Systematic Review and Meta-Analysis of "Inside-Out" versus "Outside-In" Transobturator Tapes in Management of Stress Urinary Incontinence in Women. The European Journal of Obstetrics \& Gynecology and Reproductive Biology, 162, 1-10. https://doi.org/10.1016/j.ejogrb.2012.01.004

[15] Holmgren, C., Nilsson, S., Lanner, L. and Hellberg, D. (2007) Frequency of de novo Urgency in 463 Women Who Had Undergone the Tension-Free Vaginal Tape (TVT) Procedure for Genuine Stress Urinary Incontinence-A Long-Term Follow-Up. The European Journal of Obstetrics \& Gynecology and Reproductive Biology, 132, 121-125. https://doi.org/10.1016/j.ejogrb.2006.04.012

[16] Newman, D.K., Cardozo, L. and Sievert, K.D. (2013) Preventing Urinary Incontinence in Women. Current Opinion in Obstetrics and Gynecology, 25, 388-394. https://doi.org/10.1097/GCO.0b013e328364a35d

[17] Vaughan, C.P., Auvinen, A., Cartwright, R., Johnson, T.M., Tähtinen, R.M., Ala-Lipasti, M.A., et al. (2013) Impact of Obesity on Urinary Storage Symptoms: Results from the FINNO Study. Journal of Urology, 189, 1377-1382. https://doi.org/10.1016/j.juro.2012.10.058

[18] Subak, L.L., Wing, R., Smith West, D., Franklin, F., Vittinghoff, E., Creasman, J.M., et al. (2009) Weight Loss to Treat Urinary Incontinence in Overweight and Obese Women. The New England Journal of Medicine, 360, 481-490. https://doi.org/10.1056/NEJMoa0806375

[19] Subak, L.L., Richter, H.E. and Hunskaar, S. (2009) Obesity and Urinary Incontinence: Epidemiology and Clinical Research Update. Journal of Urology, 182, S2-S7. https://doi.org/10.1016/j.juro.2009.08.071

[20] Haylen, B.T. (1989) Verification of the Accuracy and Range of Transvaginal Ultrasound in Measuring Bladder Volumes in Women. British Journal of Urology, 64, 350-352. https://doi.org/10.1111/j.1464-410X.1989.tb06040.x

[21] Haylen, B.T., Frazer, M.I., Sutherst, J.R. and West, C.R. (1989) Transvaginal Ultrasound in the Assessment of Bladder Volumes in Women. British Journal of Urology, 63, 149-151. https://doi.org/10.1111/j.1464-410X.1989.tb05152.x

[22] Haylen, B.T. and Lee, J. (2008) The Accuracy of Post-Void Residual Measurement in Women. International Urogynecology Journal and Pelvic Floor Dysfunction, 19, 603-606. https://doi.org/10.1007/s00192-008-0568-0

[23] Khullar, V., Cardozo, L.D., Salvatore, S. and Hill, S. (1996) Ultrasound: A Noninvasive Screening Test for Detrusor Instability. British Journal of Obstetrics and Gynaecology, 103, 904-908. https://doi.org/10.1111/j.1471-0528.1996.tb09910.x

[24] Robinson, D., Anders, K., Cardozo, L., Bidmead, J., Toozs-Hobson, P. and Khullar, 
V. (2002) Can Ultrasound Replace Ambulatory Urodynamics When Investigating Women with Irritative Urinary Symptoms? BJOG, 109, 145-148. https://doi.org/10.1111/j.1471-0528.2002.01021.x

[25] Lekskulchai, O. and Dietz, H.P. (2008) Detrusor Wall Thickness as a Test for Detrusor Overactivity in Women. Ultrasound in Obstetrics \& Gynecology, 32, 535-539. https://doi.org/10.1002/uog.5370

[26] Panayi, D.C., Khullar, V., Digesu, G.A., Hendricken, C., Fernando, R. and Tekkis, P. (2009) Is Ultrasound Estimation of Bladder Weight a Useful Tool in the Assessment of Patients with Lower Urinary Tract Symptoms? International Urogynecology Journal and Pelvic Floor Dysfunction, 20, 1445-1449. https://doi.org/10.1007/s00192-009-0964-0

[27] Waltregny, D. and de Leval, J. (2009) The TVT-Obturator Surgical Procedure for the Treatment of Female Stress Urinary Incontinence: A Clinical Update. International Urogynecology Journal and Pelvic Floor Dysfunction, 20, 337-348. https://doi.org/10.1007/s00192-008-0753-1

[28] Huang, A.J., Brown, J.S., Boyko, E.J., Moore, E.E., Scholes, D., Walter, L.C., et al. (2011) Clinical Significance of Postvoid Residual Volume in Older Ambulatory Women. Journal of the American Geriatrics Society, 59, 1452-1458. https://doi.org/10.1111/j.1532-5415.2011.03511.x

[29] Schuettoff, S., Beyersdorff, D., Gauruder-Burmester, A. and Tunn, R. (2006) Visibility of the Polypropylene Tape after Tension-Free Vaginal Tape (TVT) Procedure in Women with Stress Urinary Incontinence: Comparison of Introital Ultrasound and Magnetic Resonance Imaging in Vitro and in Vivo. Ultrasound in Obstetrics \& Gy necology, 27, 687-692. https://doi.org/10.1002/uog.2781

[30] Tayrac, R., Deffieux, X., Resten, A., Doumerc, S., Jouffroy, C. and Fernandez, H. (2006) A Transvaginal Ultrasound Study Comparing Transobturator Tape and Tension-Free Vaginal Tape after Surgical Treatment of Female Stress Urinary Incontinence. International Urogynecology Journal and Pelvic Floor Dysfunction, 17, 466-471. https://doi.org/10.1007/s00192-005-0043-0 